\title{
BMJ Global Health Tiered informed consent: respecting autonomy, agency and individuality in Africa
}

Nicki Tiffin ${ }^{1,2,3}$

To cite: Tiffin N. Tiered informed consent: respecting autonomy, agency and individuality in Africa. BMJ Glob Health 2018:3:e001249. doi:10.1136/ bmjgh-2018-001249

Handling editor Seye Abimbola

Received 23 October 2018 Revised 19 November 2018 Accepted 23 November 2018

\section{Check for updates}

(c) Author(s) (or their employer(s)) 2018. Re-use permitted under CC BY-NC. No commercial re-use. See rights and permissions. Published by BMJ.

${ }^{1}$ Wellcome Centre for Infectious Disease Research in Africa, University of Cape Town, Cape Town, South Africa

${ }^{2}$ Division of Computational Biology, University of Cape Town, Cape Town, South Africa ${ }^{3}$ Centre for Infectious Disease Epidemiology and Research, University of Cape Town, Cape Town, South Africa

Correspondence to Professor Nicki Tiffin; nicki.tiffin@uct.ac.za
In the developed world, societal awareness of data privacy and data protection rights is rising, particularly fuelled by recent high-profile cases of unconsented secondary data use $^{12}$ and increased recognition of reidentification risks. ${ }^{3}$ Accordingly, updated legislation ensures transparency and gives individuals greater choice and control over the use, reuse and deletion of their data (eg, the General Data Protection Regulation in the European Union). ${ }^{4}$ In this environment, researchers are engaging with a robust participant population that is generally well-informed and has agency and institutionalised support to ensure their privacy rights: the luxury of individuals understanding and determining the destination, use and reuse of their personal data and biospecimens is surely one that comes with food security, good access to healthcare, personal safety and adequate education. Evolving processes such as Dynamic Consent reflect this increasing autonomy by facilitating ongoing online engagement between researchers and participants over time. ${ }^{5}$

This contrasts with the scenario in the low-income and middle-income countries in Africa, where participant populations may be food-insecure, have limited access to education and healthcare, have limited access to communication platforms and are experiencing a dual burden of infectious and non-communicable diseases fuelled by epidemiological transition. While legislation may increasingly seek to protect individuals from data and biospecimen misuse, implementation and enforcement can be slow to follow; and African participants in research programmes to date have experienced ill-defined or absent consent processes, missing information on intended data and sample use, and convoluted consent documents that cannot be understood by a layperson. ${ }^{6} 7$

While some progress has been made to improve informed consent practices in Africa,
Summary box

There has been a rapid increase in data-generating health research being undertaken on the African continent.

- Given past ethical failures for research undertaken in Africa, ongoing and future studies must implement an ethical stringency that ensures agency and protection for all African stakeholders.

- Appropriately informed broad consent, coupled with a suitable governance structure, may be feasible for populations with high agency and institutionalised protection of personal rights, but in low-income and middle-income countries in Africa substantial proportions of the population remain vulnerable.

- Funders and researchers should ensure that the protection of participants takes precedence over other agendas; and the agency and autonomy of vulnerable African participants in research should be protected through provision of sufficient study information and an individualised, tiered consent process.

an emerging narrative posits broad consent, rather than tiered consent, as sufficient and even preferable for research participants in Africa. Within this narrative, circumstances cited to obviate the need for tiered consent include an established trust relationship between participants and a trustworthy researcher, a proposed governance structure such as an established access committee to safeguard participants concerns and community engagement processes whereby representatives from the community represent the entire community's concerns. ${ }^{8}$ Tiered consent is variously described as too difficult and time-consuming to explain to participantsespecially where translation is required, too difficult to capture and store electronically, and too difficult to query when assembling data sets for secondary use.

Relying on a consent process whereby researchers decide data/specimen reuse permissions on behalf of participants has 
uncomfortable echoes of the paternalistic, neocolonial attitudes that have historically underpinned exploitation of African participants, ${ }^{9}$ and the idea that African participants should rely on trust relationships with trustworthy researchers is unrealistic given this history. ${ }^{10}$ The reluctance to promote tiered consent seems to entrench the ideology that 'one size fits all' in Africa: it intimates that African individuals do not have the heterogeneity, individuality or imagination that might lead one participant to choose to share their data and biospecimens in all future research, while another prefers to only agree to the primary study. ${ }^{11}$ Whereas informed consent processes should support participants' individual preferences around participation, broad consent may instead be regressive for the autonomy of African research participants.

While ethical research may require a trade-off between risks and beneficence, we cannot similarly offset participant autonomy with utility of research material: these two items do not belong on the same continuum or speak to the same outcomes. Autonomy underpins participant protection, while utility underpins the research agenda: autonomy is an attribute of participants and should not be negotiable, whereas utility refers to the ability of researchers to use samples and data to answer as many research questions as completely as possible and is infinitely negotiable by the participants who share their data and biospecimens in an act of altruism. Individuals' autonomy should always be upheld through the right to refuse to participate in all or some parts of planned research: tiered consent provides individuals with the autonomy to participate in a study at a risk level with which they are comfortable, whereas broad consent demands exposure to maximum risk in order to participate.

While the good intentions of many researchers are assured, in defining consent processes and the prevailing academic narrative about informed consent in Africa they need to own their vested interests in doing research, meeting recruitment targets in funded studies and furthering research careers. Similarly, funding sourcespublic or philanthropic - may drive different agendas for the funders. These interests can surely lead to an inherent funder-centric and researcher-centric bias in the dialogue around informed consent processes. Furthermore, access committees and oversight authorities are often installed and supported by those same funders and researchersand their freedom to make truly independent decisions to protect participants cannot always be guaranteed.

Claw et al propose an ethical framework for enhancing genomic research with Indigenous communities in North America, ${ }^{12}$ which presents key components of Respect, Equity, Reciprocity and Beneficence, partnered with Transparency, Cultural Competency, Dissemination and Community Engagement to build trust. A missing component, however, that is fundamental and essential to the integrity of the framework as it might apply in Africa is participant autonomy and choice. The question must be continually asked for whom the proposed 'good cause' ${ }^{13}$ will be good, and who will make this
call-African participants, or researchers and funders collecting samples and biospecimens in Africa? Building trust is a worthy ideal, but it has not protected African participants to date, and placing trust in researchers takes control out of participants' hands and leaves them powerless. Only a transparent and binding record of specific personal choices, permissions and consent can drive autonomy and empower participants to ensure their own protection.

It may be harder to implement informed, tiered consent in a vulnerable, food-, health- and education-insecure participant population in Africa than in a developed country; but the reasons for difficulty are the same reasons that it is an ethical imperative to ensure the protection of autonomy, dignity and most importantly informed choice for those individuals in every aspect of the use of their data and samples. Broad consent does not fulfil this imperative and runs the risk of becoming a whitewash for a return to exploitative research practices in Africa. If tiered informed consent is harder to realise than broad consent in this environment, this surely indicates that more work is required to adequately inform participants, protect their autonomy and provide them with individual choices: it is not a reason to use broad consent to gloss over the nuances and reduce the agency of African individuals over their participation in research. Ongoing processes should address how each individual participant may be assured autonomy, agency and individualised choice when deciding to what extent they will participate in research.

Acknowledgements NT is supported by Wellcome (203135/Z/16/Z), and the National Institutes of Health (awards H3ABioNet: R01HD080465 and B-Positive: U24HG006941).

Contributors Nicki Tiffin conceived of and wrote the submitted article.

Competing Interests The author has no competing interests.

Patient consent for publication Not required.

Provenance and peer review Not commissioned; externally peer reviewed.

Data sharing statement

No additional data are available.

Open access This is an open access article distributed in accordance with the Creative Commons Attribution Non Commercial (CC BY-NC 4.0) license, which permits others to distribute, remix, adapt, build upon this work non-commercially, and license their derivative works on different terms, provided the original work is properly cited, appropriate credit is given, any changes made indicated, and the use is non-commercial. See: http://creativecommons.org/licenses/by-nc/4.0

\section{REFERENCES}

1. Metcalf J. Facebook may stop the data leaks, but it's too late: cambridge analytica's models live on. In: MIT technology review internet, 2018. Available from: https://www.technologyreview.com/ s/610801/facebook-may-stop-the-data-leaks-but-its-too-latecambridge-analyticas-models-live-on/ [Accessed 20 May 2018].

2. Kolata $\mathrm{G}$, Murphy $\mathrm{H}$. The golden state killer is tracked through a thicket of DNA, and experts shudder. The New York times, 2018. Available from: https://www.nytimes.com/2018/04/27/health/dnaprivacy-golden-state-killer-genealogy.html [Accessed 20 May 2018].

3. Culnane C, Rubinstein BIP, Teague V, 2017. Health data in an open world. ArXiv171205627 Cs. Available from: http://arxiv.org/abs/1712. 05627

4. European Union. 2018 reform of EU data protection rules. In: European commission - European commission, 2018. Available 
from: https://ec.europa.eu/commission/priorities/justice-andfundamental-rights/data-protection/2018-reform-eu-data-protectionrules_en [Accessed 7 Jun 2018].

5. Kaye J, Whitley EA, Lund D, et al. Dynamic consent: a patient interface for twenty-first century research networks. Eur J Hum Genet 2015;23:141-6.

6. Tiffin $\mathrm{N}$. Unique considerations for advancing genomic medicine in African populations. Per Med 2014;11:187-96.

7. Wright GE, Adeyemo AA, Tiffin N. Informed consent and ethical reuse of African genomic data. Hum Genomics 2014;8:18.

8. Tindana P, de Vries J. Broad consent for genomic research and biobanking: perspectives from low- and middle-income countries. Annu Rev Genomics Hum Genet 2016;17:375-93.

9. Kim JU, Oleribe O, Njie R, et al. A time for new north-south relationships in global health. Int J Gen Med 2017;10:401-8.
10. Schroeder D, Cook J, Hirsch F. Ethics dumping: case studies from north-south research collaborations. Springer International Publishing, 2017.

11. Moodley K, Sibanda N, February K, et al. "It's my blood": ethical complexities in the use, storage and export of biological samples: perspectives from South African research participants. BMC Med Ethics 2014;15:4.

12. Claw KG, Anderson MZ, Begay RL, et al. A framework for enhancing ethical genomic research with Indigenous communities. Nat Commun 2018:9:2957.

13. van Schalkwyk G, de Vries J, Moodley K. "It's for a good cause, isn't it?" - exploring views of South African TB research participants on sample storage and re-use. BMC Med Ethics 2012;13:19. 